\title{
ANÁLISE TÊMPORO-ESPACIAL DOS FOCOS DE CALOR NO ESTADO DO PIAUÍ, BRASIL
}

\author{
Jhony Gonçalves de Lima ${ }^{(a)}$, Fabiana Moreira dos Santos ${ }^{(\mathrm{b})}$, Emanuel Lindemberg Silva \\ Albuquerque $^{(\mathrm{c})}$
}

(a) Coordenação do Curso de Geografia, Universidade Federal do Piauí, jhonygoncalvesdelima@ gmail.com

(b) Coordenação do Curso de Geografia, Universidade Federal do Piauí, fabybb_@hotmail.com

(c) Coordenação do Curso de Geografia, Universidade Federal do Piauí, lindemberg @ufpi.edu.br

\section{Eixo: GEOTECNOLOGIAS E MODELAGEM ESPACIAL EM GEOGRAFIA FÍSICA}

\begin{abstract}
Resumo
As queimadas sempre estiveram ligadas às diversas atividades humanas. Não obstante, é de suma importância distinguir as queimadas dos focos de calor, sendo que estes se configuram como qualquer temperatura registrada acima de $47^{\circ} \mathrm{C}$ e que são detectados a partir de satélites específicos. O objetivo desse estudo é analisar, do ponto de vista têmporo-espacial, os focos de calor registrado no estado do Piauí nos anos de 2010, 2013 e 2016, contextualizando os dados ao nível das bacias hidrográficas. Os procedimentos metodológicos contemplam revisão bibliográfica e aquisição da base cartográfica. Utilizaram-se os registros do satélite NOAA 18 (National Oceanic Atmospheric Administration), obtidos no Banco de Dados de Queimadas (BDQueimadas-INPE). De posse dos mesmos, foi possível espacializar em ambiente de Sistema de Informação Geográfica tal fenômeno. Conclui-se que houve um aumento considerável nos focos de calor entre os anos de 2010, 2013 e 2016, respectivamente, com $1.914,3.506$ e 7.662 registros.
\end{abstract}

Palavras chave: Geotecnologias, Mapeamento, Bacias hidrográficas.

\section{Introdução}

Desde os primórdios da humanidade o fogo sempre esteve ligado às atividades humanas. Antes de dominá-lo, o homem precisava esperar que este surgisse influenciado por outros fatores, tais como raios, para assim poder manejá-lo. Gomes et al. (2010), afirmam que o Brasil, em linhas gerais, o fogo, como sinônimo de queimadas, é utilizado como uma ferramenta no manejo das atividades agropecuárias e no preparo da terra, mas também é bastante empregado na queima do lixo doméstico e restos vegetais.

Neste contexto, destaca-se que as queimadas podem ser causadas por ações antrópicas ou processos de origem natural, mas ambas trazem prejuízos de grandes proporções ao meio ambiente, impedindo a reestruturação deste e a sobrevivência de algumas espécies da fauna e da flora local. Por outro lado, o foco de calor é a deteç̧ão, por sensores embarcados em satélites, de um ponto na superfície terrestre que apresenta temperatura de brilho, isto é, a temperatura que chega ao sensor, da ordem de $47^{\circ} \mathrm{C}$ (SILVA FILHO et al., 2009). 
Ao considerar o recorte espacial da pesquisa, menciona-se que o estado do Piaú possue uma grande diversidade em seu padrão físico-geográfico, relacionada com suas características climáticas, tipos de vegetação, feições geomorfológicas, pedológicas, dentre outros aspectos predominantes. O Estado se localiza em uma região de transição dentro do Nordeste brasileiro, compreendendo setores com Cerrado, Mata dos Cocais, Zona Costeira e Caatinga (PIAUÍ, 2010).

Nesse sentido, ao analisar as normais climatológicas (dos últimos 30 anos) do Piauí, com base nos dados do Instituto Nacional de Meteorologia (INMET), constata-se que no segundo semestre do ano (julho a dezembro) são registrados os menores índices pluviométricos, associado ainda ao baixo nível de umidade. Por outro lado, nos primeiros meses do ano (janeiro a junho) corresponde ao período chuvoso ou mais úmido, mas não de forma uniforme e constante, típico de área semiárida ou área de entorno.

Com base nestes aspectos, em associação ao contexto histórico de uso e ocupação do território piauiense, o presente trabalho visa realizar uma análise têmporo-espacial das incidências de focos de calor no estado do Piauí nos anos de 2010, 2013 e 2016, contextualizando sua evolução e/ou regressão ao nível das 12 bacias hidrográficas que drenam o Estado. Destaca-se que o satélite utilizado foi o NOAA 18 (National Oceanic and Atmospheric Admnistration) / sensor AVHRR (Advanced Very High Resolution Radiometer).

Zanella et al. (2013), comentam que as bacias hidrográficas compõem um sistema, no qual a relação entre os diferentes componentes formam uma paisagem peculiar, marcada por uma dinâmica específica, em que os seus componentes não se limitam aos elementos naturais, mas envolvem também a sociedade. Neste caso, considerando as ocorrências dos focos de calor por meio da análise quali-quantitativa.

\section{Metodologia}

O sensoriamento remoto é, em particular, uma importante ferramenta para detecção de focos de calor, em virtude de sua abrangência espacial, temporal, espectral e radiométrica na obtenção de dados. No presente trabalho foram utilizados os registros do satélite NOAA 18. Este foi desenvolvido pela NASA como um sistema de satélite meteorológico (órbita polar), incluindo sensores/bandas do infravermelho.

A escolha deste satélite é justificada pelo fato de seu sensor AVHRR (resolução espacial de 1x1 km) abranger o comportamento dos focos de calor, de maneira que qualquer temperatura registrada acima de $47^{\circ} \mathrm{C}$ configura-se como uma ocorrência. Os dados referentes aos focos de calor dos anos de 2010, $2013 \mathrm{e}$ 2016 do estado do Piaú foram obtidos por meio de download do site do Instituto Nacional de Pesquisas Espaciais (INPE), através do Banco de Dados de Queimadas de Centro de Previsão de Tempo e Estudos Climáticos (CPTEC). 


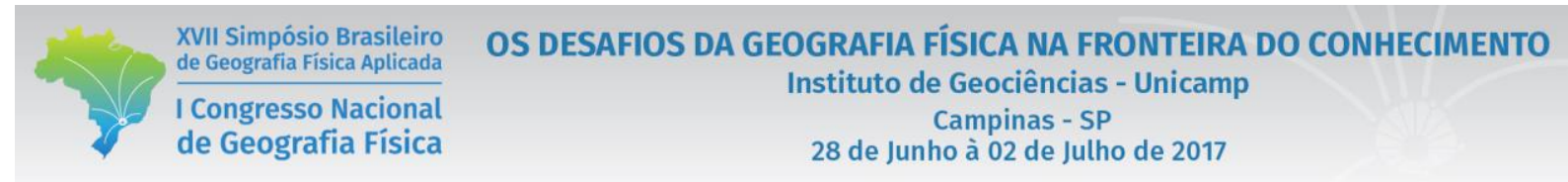

Na sequência, foi realizado o tratamento e organização da base de dados em ambiente de Sistema de Informação Geográfica (SIG), utilizando recursos dos softwares QGIS 2.18.3 e ArcGis 10.2. Estes dados constituem-se de pontos que possuem informações básicas sobre os focos de calor. Cada ponto possui as seguintes variáveis: coordenadas geográficas (latitude e longitude), data da observação do foco de calor (dia, mês e ano), tipo de satélite e município.

A análise espacial (cruzamento dos dados georreferenciados) dos focos de calor de deu em dois níveis para cada ano em destaque nessa pesquisa. O primeiro ao nível de Estado (poligonal do Piauí) e o segundo ao nível das bacias hidrográficas, a saber: Bacias Difusas do Alto Parnaíba, Bacias do Uruçuí Preto, Bacia do Gurguéia, Bacias Difusas da Barragem de Boa Esperança, Bacias Difusas do Médio Parnaíba, Bacia de Itaueira, Bacia do Canindé, Bacia do Poti, Bacias Difusas do Baixo Parnaíba, Bacia do Longá, Bacia do Piranji e Bacias Difusas do Litoral. Como produto, derivou-se uma análise quali-quatitativa, do ponto de vista espacial, dos focos de calor no estado do Piauí.

\section{Resultados e Discussões}

De acordo com os dados analisados, constatou-se um total de 13.082 focos de calor no estado do Piauí, distribuídos da seguinte forma, a saber: 2010, com 1.914 registros; 2013, com 3.506 registros e; 2016, com 7.662 registros. Em síntese, observou-se uma tendência expressiva e progressiva no aumento das ocorrências dos focos de calor, como pode ser visualizado na figura 1 e tabela 1.

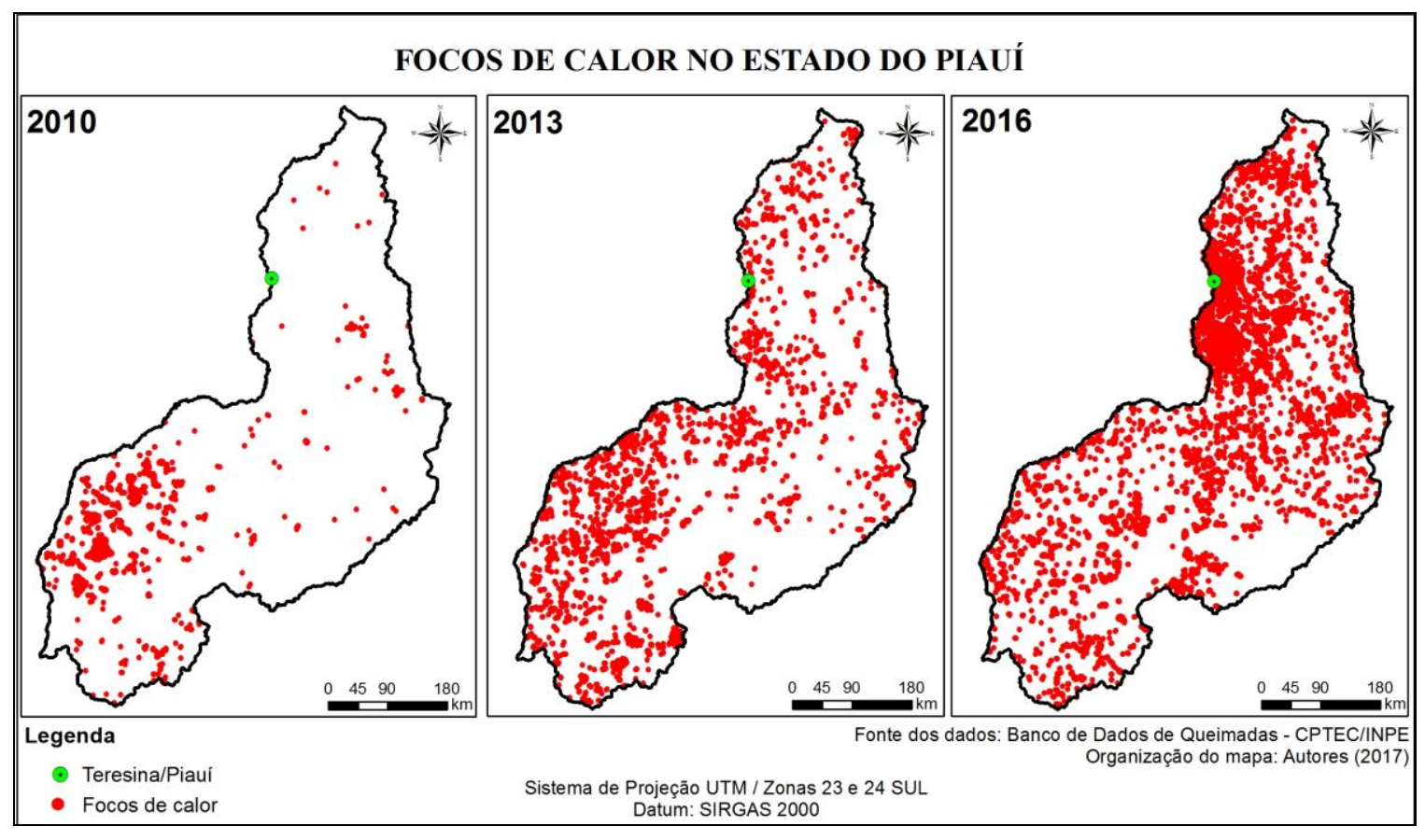

Figura 1 - Focos de calor registrado no estado do Piauí nos anos de 2010, 2013 e 2016 
Tabela I - Focos de calor resistado nas bacias hidrográficas no estado do Piauí em 2010, 2013 e 2016

\begin{tabular}{|l|c|c|c|}
\hline \multicolumn{1}{|c|}{$\begin{array}{c}\text { BACIAS HIDROGRÁFICAS } \\
\text { ESTADO DO PIAUÍ }\end{array}$} & \multicolumn{3}{c|}{ ANOS } \\
\cline { 2 - 4 } & $\mathbf{2 0 1 0}$ & $\mathbf{2 0 1 3}$ & $\mathbf{2 0 1 6}$ \\
\hline Bacias Difusas do Alto Parnaíba & 448 & 459 & 371 \\
\hline Bacias do Uruçuí Preto & 991 & 540 & 304 \\
\hline Bacia do Gurguéia & 272 & 920 & 1004 \\
\hline Bacias Difusas da Barragem de Boa Esperança & 87 & 224 & 130 \\
\hline Bacias Difusas do Médio Parnaíba & 1 & 117 & 829 \\
\hline Bacia de Itaueira & 6 & 150 & 221 \\
\hline Bacia do Canindé & 41 & 537 & 1832 \\
\hline Bacia do Poti & 60 & 268 & 1635 \\
\hline Bacias Difusas do Baixo Parnaíba & 0 & 81 & 606 \\
\hline Bacia do Longá & 8 & 179 & 692 \\
\hline Bacia do Piranji & 0 & 0 & 8 \\
\hline Bacias Difusas do Litoral & 0 & 31 & 30 \\
\hline Total & $\mathbf{1 . 9 1 4}$ & $\mathbf{3 . 5 0 6}$ & $\mathbf{7 . 6 6 2}$ \\
\hline
\end{tabular}

Ao considerar a espacialização dos focos de calor em relação à área delimitada, verifica-se uma predominância no setor Sudoeste/Oeste do Estado. A variação mais expressiva destaca-se na evolução do ano de 2013 (3.506 registros) para 2016, quando atingiu o ápice, com um total de 7.662 focos registrados, representando um aumento de 75\% quando comparado ao ano de 2010.

Vale destacar que o estado do Piaú encontra-se inserido em setores do Nordeste semiárido brasileiro e área de entorno, em que predomina, sobretudo, a irregularidade das precipitações pluviométricas no tempo e no espaço. Este fator tende a potencializar as queimadas (registrada pelo satélite como foco de calor), tendo em vista que o período seco é associado às temperaturas elevadas e baixa umidade do ar.

Ao analisar o cenário dos focos de calor nas bacias hidrográficas que drenam o estado do Piauí, constatase um aumento progressivo (2010/2013/2016) nas bacias do: Gurguéia, Difusas da Barragem de Boa Esperança, Difusas do Médio Parnaíba, Itaueira, Canindé, Poti, Difusas do Baixo Parnaíba, Longá, Piranji e Difusas do Litoral. Enquanto houve redução, no cenário temporal adotado, nas bacias: Difusas do Alto Parnaíba e Uruçuí Preto.

Diante deste cenário alarmante, salienta-se que as bacias hidrográficas que mais registraram focos de calor, no somatório dos três anos, foram às bacias do: Poti, Gurguéia e Canindé, com, respectivamente, $1.963,2.196$ e 2.410 registros captados. Do ponto de vista percentual, as bacias que mais registraram evolução progressiva/sequencial para o recorte temporal adotado foram as: Bacias Difusas do Médio Parnaíba (99,8\%), Bacia do Canindé $(97,7 \%)$ e Bacia do Poti (96,3\%), com um adicional de 828, 1.791 e 1.575 focos de calor, respectivamente. 


\section{Considerações Finais}

A partir da análise feita no presente estudo, pode-se concluir que existe uma relação considerável no aumento progressivo dos focos de calor no estado do Piauí, passando de 1.914 no ano de 2010 para 7.662 no ano de 2016. Do ponto de vista espacial, nota-se uma maior concentração dos focos de calor nas seções Sudoeste e Oeste do Piaú.

Ao analisar o contexto das 12 (doze) bacias hidrográficas que drenam o Estado, constata-se que os setores que mais registraram focos de calor foram às bacias dos rios Poti (1.963ocorrências), Gurguéia (2.196 ocorrências) e Canindé (2.410 ocorrências). Percentualmente, as Bacias Difusas do Médio Parnaíba, Bacia do Canindé e Bacia do Poti, registaram, respectivamente, um aumento de 99,8\%, 97,7\% e 96,3\%, no comparativo 2010/2016.

Em suma, corrobora-se que a análise empreendida possibilita uma percepção sinóptica da distribuição espacial e temporal dos focos de calor no estado do Piauí, sendo que os dados de sensoriamento remoto (satélite NOAA 18 / sensor AVHRR) foram de fundamental importância para alcançar tais resultados, podendo ser ainda utilizado para outras análises e reflexões a respeito do espaço geográfico.

\section{Bibliografia}

BRASIL Instituto Nacional de Meteorologia - INMET. Normais climatológicas. Disponível em: http//www.inmet.gov.br. Acesso em: 01/02/2017.

BRASIL. Instituto Nacional de Pesquisas Espaciais - INPE. Dados pontuais de focos de calor. Programa de Monitoramento de Focos. Disponível em: http://sigma.cptec.inpe.br/queimadas/. Acesso em: 01/02/2017.

GOMES, D. D. M.; MEDEIROS, C. N. de; ALBUQUERQUE, E. L. S. Análise têmporo-espacial das ocorrências de focos de calor no estado do Ceará: configuração dos cenários no contexto das unidades fitogeográficas e das Macrorregiões de Planejamento. Texto para Discussão, Fortaleza, nº. 90, 01-28, dez. 2010.

PIAUÍ. Secretaria do Meio Ambiente e Recursos Hídricos. Plano Estadual de Recursos Hídricos - Relatório Síntese. Teresina/PI: SEMAR, 2010.

SILVA FILHO, E. B. da; TELES, L. J. S; SANTOS NETO, L. A. dos. Ocorrências de focos de calor no estado de Rondônia em 2007. Sociedade \& Natureza, Uberlândia, 21 (2): 123-140, ago. 2009.

ZANELLA, M. E; OLIMPIO, J. L. S; COSTA, M. C. L; DANTAS, E. W. C. Vulnerabilidade socioambiental do Baixo curso da Bacia Hidrográfica do Rio Cocó, Fortaleza-CE. Revista Sociedade e Natureza, no 25, v. 2, p. $317-$ 332, 2013. 